\section{COMPLEMENT AND GRANULOCYTE ACTIVATION IN TWO DIFFERENT TYPES OF HEPARINIZED EXTRACORPOREAL CIRCUITS}

Complement and granulocyte activation were studied in cardiopulmonary bypass circuits completely coated with either end-attached covalent-bonded heparin, the Carmeda BioActive Surface, or with the Duraflo II bonded heparin, in combination with reduced systemic heparinization (activated clotting time $>250$ seconds). The control groups were perfused with uncoated circuits and full heparin dose (activated clotting time $>480$ seconds). Altogether 67 patients undergoing elective first-time myocardial revascularization were investigated, having extracorporeal perfusion with a Duraflo II coated circuit ( $n=17$ ), an identical but uncoated circuit ( $n=17$ ), a Carmeda coated circuit $(n=17)$, or an equivalent uncoated circuit $(n=16)$. During cardiopulmonary bypass, the $\mathrm{C} 3$ activation products $\mathrm{C} 3 \mathrm{~b}, \mathrm{iC} 3 \mathrm{~b}$, and $\mathrm{C} 3 \mathrm{c}$ (C3bc) and the terminal SC5b-9 complement complex increased markedly in all four groups compared with baseline, but significantly less in the two coated groups than in their control groups. Additionally, a significantly lower concentration of $\mathrm{C} 3 \mathrm{bc}$ was observed in the Carmeda coated group, with maximal increase of median $28 \mathrm{AU} / \mathrm{ml}$ compared with $50 \mathrm{AU} / \mathrm{ml}$ in the Duraflo II coated group ( $p=0.003$ ). Similarly, in the Carmeda coated group, the maximal increase of terminal complement complex was considerably lower $(0.8 \mathrm{AU} / \mathrm{ml})$ than the levels recognized in the Duraflo II coated group $(2.4 \mathrm{AU} / \mathrm{ml})(p<$ $0.001)$. The release of the granulocyte activation enzymes myeloperoxidase and lactoferrin increased from the beginning of the operation, with peak levels at the end of bypass. A significant reduction of lactoferrin release was recognized when comparing the coated groups with the control groups. The difference between the two coated groups (Carmeda $229 \mu \mathrm{g} / \mathrm{L}$; Duraflo II $332 \mu \mathrm{g} / \mathrm{L} ; p=$ 0.05) was marginally significant. For myeloperoxidase, no significant differences were observed between the coated and uncoated groups. In conclusion, both types of heparin-coated circuits reduced complement activation and release of lactoferrin, but the Carmeda circuit proved to be more effective than the Duraflo II equipment. (J THORAC CARdrovasC SURG 1995;110:1623-32)

Eivind Øvrum, MD, ${ }^{a}$ Tom Eirik Mollnes, MD, PhD, ${ }^{b}$ Erik Fosse, MD, PhD, ${ }^{c}$

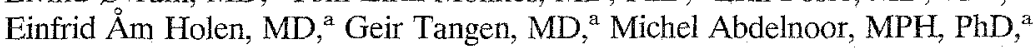
Mari-Anne L. Ringdal, CCP, ${ }^{a}$ Rolf $\emptyset y s t e s e, C C P,{ }^{a}$ and Per Venge, MD, PhD, ${ }^{d}$ Oslo and Troms $\varnothing$, Norway, and Uppsala, Sweden
B inding of heparin to surfaces in contact with blood during cardiopulmonary bypass (CPB) has been shown to reduce activation of biologic cascades. ${ }^{1-5}$ This indication of improved hemocompat-

From the Department of Cardiac Surgery and Anesthesiology, Oslo Heart Center, Oslo, Norway ${ }^{\text {a }}$; the Department of Immunology and Transfusion Medicine, Nordland Central Hospital, and University of Troms $\emptyset$, Norway ${ }^{b}$; Surgical Department A, The National Hospital, Oslo, Norwayc; and the Department of Clinical Chemistry, Uppsala University Hospital, Uppsala, Sweden. ${ }^{\mathrm{d}}$

Received for publication Dec. 23, 1994.

Accepted for publication April 6, 1995.

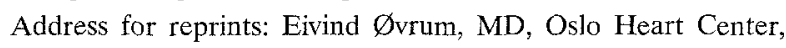
Pilestredet 32, 0027 Oslo, Norway. ibility may contribute to decrease the risk of postperfusion injury. ${ }^{6,7}$ In addition, heparinized circuits have allowed reduced doses of systemic heparin, with the potential benefits of reduced postoperative bleeding and less need for protamine. ${ }^{8,9}$

Heparin can be attached to polymers with various ionic preparations or by covalent binding to the surface. ${ }^{10}$ At the present time, two different types of heparinized extracorporeal circuits are available for clinical use. The Duraflo II surface (Baxter Healthcare Corp., Bentley Laboratories Division, Irvine,

Copyright (C) 1995 by Mosby-Year Book, Inc. $0022-5223 / 95 \$ 5.00+0 \quad 12 / 1 / 65334$ 
Table I. Demographic data and operative details of the four groups*

\begin{tabular}{lcccc}
\multicolumn{1}{c}{ Clinical parameters } & \multicolumn{4}{c}{ Median (range) } \\
\cline { 2 - 5 } & $\begin{array}{c}\text { Duraflo II coated } \\
(n=17)\end{array}$ & $\begin{array}{c}\text { Duraflo II control } \\
(n=17)\end{array}$ & $\begin{array}{c}\text { CBAS coated } \\
(n=17)\end{array}$ & $\begin{array}{c}\text { CBAS control } \\
(n=16)\end{array}$ \\
\hline Age (yr) & $62(47-73)$ & $68(44-74)$ & $66(40-72)$ & $62(48-72)$ \\
Female/male & $3 / 14$ & $5 / 12$ & $1 / 16$ & $2 / 14$ \\
Weight (kg) & $76(54-105)$ & $76(60-105)$ & $79(65-96)$ & $83(49-109)$ \\
Ejection fraction (\%) & $68(56-89)$ & $73(55-86)$ & $72(56-93)$ & $70(48-86)$ \\
Internal mammary artery graft (patients) & $17 / 17$ & $17 / 17$ & $17 / 17$ & $16 / 16$ \\
No. of distal anastomoses & $4(3-5)$ & $4(2-5)$ & $4(2-6)$ & $4(2-6)$ \\
Extracorporeal time (min) & $43(34-53)$ & $46(26-59)$ & $47(29-70)$ & $51(28-69)$ \\
Ischemic time (min) & $24(15-34)$ & $25(16-36)$ & $27(17-50)$ & $31(16-46)$ \\
Lowest hematocrit value on bypass (\%) & $24(19-30)$ & $23(19-25)$ & $23(20-26)$ & $23(19-27)$ \\
\hline
\end{tabular}

*No significant intergroup differences were detected.

Calif.) binds heparin partly ionically by means of a proprietary process. ${ }^{10}$ The Carmeda BioActive Surface (CBAS, Medtronic, Inc., Minneapolis, Minn.) covalently binds end point-attached degraded heparin. ${ }^{11}$ Reduced complement and granulocyte activation has been demonstrated individually for both systems, ${ }^{2-5,12}$ although most reports have been based on results in which only the oxygenators and tubings were heparinized. However, comparison of the two systems with regard to degree of activation of biomarkers has not previously been reported.

The purpose of the present study was to compare the effects of the CBAS system and the Duraflo II circuit on the most relevant complement markers (C3 activation products and terminal complement complex [TCC]), and the granulocyte activation as assessed by release of myeloperoxidase and lactoferrin, in patients undergoing elective coronary artery bypass operations.

\section{Patients and methods}

Patients admitted for first-time elective coronary artery bypass grafting with two- or three-vessel disease were eligible for the study. They had a low operative risk profile. Urgent operation was a cause for exclusion, as were redo operations, age more than 75 years, and impaired left ventricular function. Neurologic disorders and liver and renal failure were also reasons for exclusion. Anticoagulation or antiplatelet therapy was discontinued 7 days before the operation in all patients.

Informed consent was obtained from all patients and the study protocol was approved by the regional ethical committee. All operations were performed by one of two surgeons (E. Ø., G.T.).

For the Duraflo II part of the study, 34 patients were prospectively randomized to have CPB with a heparincoated circuit (coated group) or with an uncoated but otherwise identical circuit (control group). No visual differences between the two extracorporeal circuits were present, and the surgical team was blinded to the randomization.

Duraflo II group $(n=17)$. All surfaces in contact with blood were coated with a water-insoluble heparin complex. The circuit included silicone and polyvinylchloride tubings connected to a hard-shell cardiotomy reservoir (DII BCR 3500, Baxter Bentley), a soft-shell venous reservoir (DII BMR-1900, Baxter Bentley), a woven hollow polypropylene-fiber membrane oxygenator (Univox Gold; Baxter Bentley, surface area $1.80 \mathrm{~m}^{2}$ ), and a $25 \mu \mathrm{m}$ arterial filter (DII AF-1025, Baxter Bentley). Systemic heparin (Nycomed Pharma, Oslo, Norway) was given in a bolus dose of $100 \mathrm{IU} / \mathrm{kg}$. Activated clotting time (ACT) (HemoTec, Inc., Englewood, Colo.) should exceed 250 seconds before institution of CPB. The dose of protamine sulfate for neutralization of heparin was $1.3 \mathrm{mg} / 100 \mathrm{IU}$ heparin. The extracorporeal bypass circuit was disconnected before administration of protamine.

Duraflo II control group $(n=17)$. The extracorporeal circuit was uncoated but otherwise identical to the heparin-coated equipment. Heparin was administered in a dose of $400 \mathrm{IU} / \mathrm{kg}$, and the ACT exceeded 480 seconds before CPB was begun. The protamine/heparin ratio was similar to that in the coated group.

The patients in whom the CBAS system was used were entered in the study immediately after the Duraflo II series had been terminated. The protocol for patient selection and study design were exactly the same as for the Duraflo II series.

CBAS group $(n=17)$. Every part of the extracorporeal equipment in contact with the patient's blood was coated with end-attached covalent-bonded heparin. The circuit included polyvinylchloride tubings connected to a hardshell cardiotomy reservoir (CB SK 1351, Medtronic), a collapsible venous reservoir bag (CB MVR 1600, Medtronic), a woven hollow polypropylene-fiber membrane oxygenator (CB Maxima Plus 3380, Medtronic, surface area $2.0 \mathrm{~m}^{2}$ ), and a $20 \mu \mathrm{m}$ arterial filter (CB M-20, Medtronic). As for the Duraflo II coated group, systemic heparin was given in a bolus dose of $100 \mathrm{IU} / \mathrm{kg}$ and $\mathrm{ACT}$ exceeded 250 seconds before CPB.

CBAS control group $(n=16)$. The extracorporeal circuit was uncoated but otherwise identical to the coated 
Table II. Heparin and protamine sulfate doses in the four groups

\begin{tabular}{lccccc}
\hline \multicolumn{1}{c}{ Doses } & \multicolumn{4}{c}{ Median (range) } \\
\cline { 2 - 6 } & $\begin{array}{c}\text { Duraflo II coated } \\
(n=17)\end{array}$ & $\begin{array}{c}\text { Duraflo II control } \\
(n=17)\end{array}$ & $\begin{array}{c}\text { CBAS coated } \\
(n=17)\end{array}$ & $\begin{array}{c}\text { CBAS control } \\
(n=16)\end{array}$ \\
\hline Heparin/body weight (IU/kg) & $130(105-179)^{*}$ & $450(350-620)$ & $150(104-213)^{*}$ & $426(407-522)$ \\
Protamine sulfate/body weight (mg/kg) & $1.7(1.4-2.4)$ & $5.4(5.1-7.1)$ & $1.7(1.3-2.8)$ & $5.4(5.0-6.8)$ \\
Protamine/heparin & $1.32(1.25-1.59)$ & $130(1.24-1.43)$ & $1.29(0.88-1.50)$ & $1.29(1.06-1.47)$ \\
\hline
\end{tabular}

"Between the coated groups there was significant difference in the heparin doses $(p<0.05)$.

equipment, and the heparin and protamine administration was similar to that used in the Duraflo II control group.

In all groups, additional heparin was given if the ACT was below the lower limit. The postoperative ACT should be less than 130 seconds, and protamine was added if necessary.

Operation and blood conservation. Extracorporeal circulation was performed with the use of a Stöckert roller pump with the pulsatile flow control device (PFC III, Stöckert Instrumente GmbH, Munich, Germany). Mild hypothermia (blood temperature, $32^{\circ} \mathrm{C}$ ) was instituted immediately after CPB was begun. The heart-lung machine was primed with $2000 \mathrm{ml}$ of Ringer's acetate, and hemodilution was even more accentuated by removal of autologous blood for blood conservation, ${ }^{13}$ which aimed at an intraoperative hematocrit value of more than $22 \%$. The ventilation of the lungs was terminated during $\mathrm{CPB}$ and reinstituted a few minutes before conclusion of $\mathrm{CPB}$.

Myocardial protection consisted of antegrade administration of crystalloid cardioplegic solution (St. Thomas' Hospital No. 2) and topical cooling with ice slush. Cardiotomy suction was used during the entire period of heparinization. Anticoagulation was reversed with protamine sulfate. The mediastinal shed blood was autotransfused hourly in a closed system up to 18 hours after the operation.

ACT was measured before the operation, after heparin administration, before CPB, 10 minutes after the start of $\mathrm{CPB}$, at 20-minute intervals during CPB, after protamine administration, and 2 hours after the operation.

Test blood sampling. Samples of blood treated with ethylenediaminetetraacetic acid were drawn from the central venous cannula at the following intervals: (1) after induction of anesthesia; (2) immediately after institution of CPB; (3) after release of the aortic crossclamp; (4) at the end of CPB, after the onset of lung ventilation; (5) 2 minutes after administration of protamine; (6) 2 hours after the operation; and (7) 18 hours after the operation.

All samples were immediately cooled on ice and centrifuged, and plasma was stored at $-70^{\circ} \mathrm{C}$ until assayed in one batch for all groups. The analyses were performed by investigators blinded with regard to allocation of the patients to the four groups.

Analysis. C3 activation was measured in a doubleantibody enzyme immunoassay. ${ }^{14}$ The polystyrene plates were coated with a mouse monoclonal antibody (bH6) specific for a C3 neoepitope expressed in C3b, iC $3 b$, and $\mathrm{C} 3 \mathrm{c}$, but not in the native $\mathrm{C} 3$ component. The concentration of the SCSb-9 TCC was quantified in a similar enzyme immunoassay with a mouse monoclonal antibody (aE11) specific for a neoepitope expressed only in activated C9. ${ }^{15}$ $\mathrm{C} 3 \mathrm{bc}$ and $\mathrm{TCC}$ are indicated as arbitrary units (AU) per milliliter, referred to a standard of zymosan-activated serum defined to contain $1000 \mathrm{AU} / \mathrm{ml}$.

Myeloperoxidase was analyzed according to instructions given by the manufacturer (Pharmacia Diagnostics, Uppsala, Sweden), and lactoferrin was analyzed in plasma by radioimmunologic techniques. ${ }^{16}$

The total plasma concentration of heparin was analyzed as a complex with the antithrombin present in plasma (Coatest Heparin, Chromogenix, Mölndal, Sweden).

Statistics. The four groups were compared by means of the Kruskal-Wallis test for continuous variables. Discrete variables were treated by means of contingency tables, with Yates' correction and Fisher's test when one of the expected cell values was less than 5. For the serial measurements of C3bc, TCC, lactoferrin, and myeloperoxidase, the sample points were related to the progress of the operation and differed in each patient. Therefore comparisons at each sample point were not considered relevant. Hence the values were treated individually for each patient, the maximal increase being calculated as the difference between the individual peak value (regardless sample point) and the value obtained immediately after the start of CPB. The summary measurements in each group were compared by means of the Mann-Whitney test. ${ }^{17}$ Analysis of the time-dependent changes within each group were done by means of the paired Student's $t$ test and the Wilcoxon paired test. ${ }^{18}$ The values are presented as medians with quartiles or range when indicated. A $p$ value less than 0.05 was considered significant.

\section{Results}

The demographic data are shown in Table I. No significant differences in any parameters were observed. Higher amounts of heparin and more supplemental doses were required in the CBAS coated group than in the Duraflo II coated group $(p<0.05)$ to achieve the lower limit of ACT (Table II). Despite this fact, the ACTs during CPB were significantly higher in the Duraflo II coated group ( $p<$ 0.01) (Fig. 1). This difference was confirmed by estimation of total plasma heparin, which showed higher levels in the Duraflo II coated group during CPB (Fig. 2). An index of the summary values of the heparin concentration during $\mathrm{CPB} /$ systemic heparin dose revealed a highly significant difference between the groups $(p<0.001)$. The actual doses of heparin 


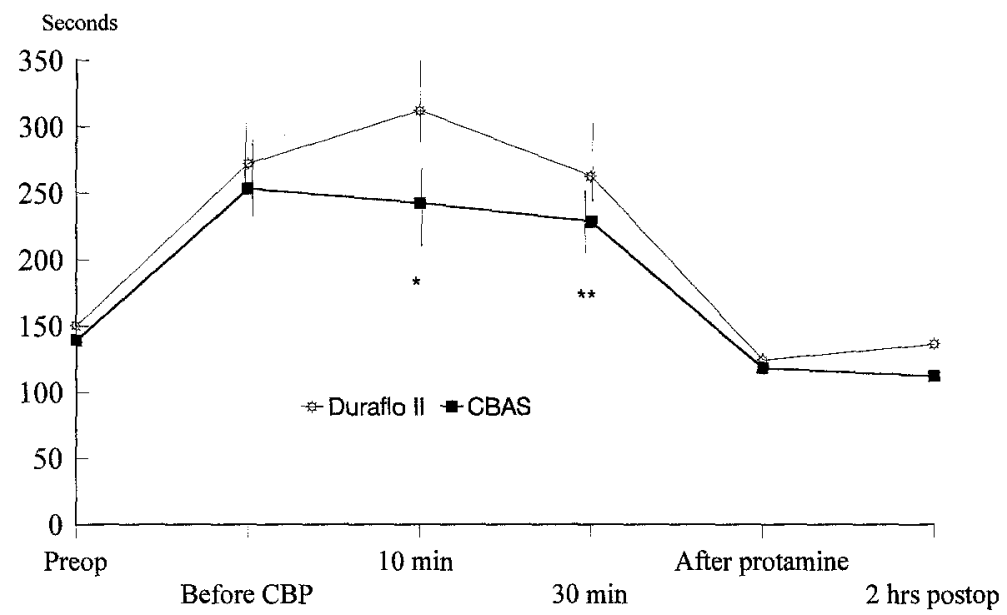

Fig. 1. Perioperative ACT in the two heparin-coated groups. Significant differences $\left({ }^{*} p<0.001,{ }^{* *} p<\right.$ 0.01 ) were observed during CPB.

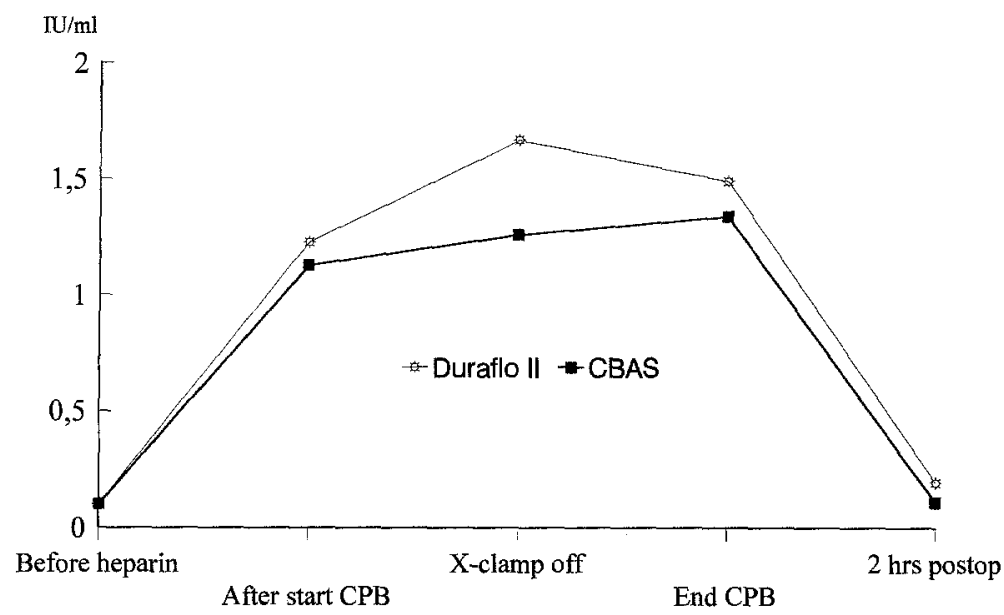

Fig. 2. Perioperative plasma concentration of heparin in the two heparin-coated groups. $X$-clamp, Crossclamp.

in the coated groups were reduced to approximately $30 \%$ of the doses in the control groups.

The postoperative parameters such as mediastinal drainage, hemoglobin concentration at discharge, and kidney function were similarly favorable in all four groups, with no significant intergroup differences (Table III). All patients survived.

The mean hematocrit values during $\mathrm{CPB}$ and body weights were similar in the groups, and all figures for the activation products are given uncorrected for hemodilution.

$\mathrm{C} 3$ activation products (C3bc). The $\mathrm{C} 3$ activation products $\mathrm{C} 3 \mathrm{~b}, \mathrm{iC} 3 \mathrm{~b}$, and $\mathrm{C} 3 \mathrm{c}$ increased markedly in all groups compared with baseline values $(p<$ 0.001 ), reaching a peak level at the end of the operation (Fig. 3). The levels were significantly lower in the CBAS coated group than in the CBAS control group $(p=0.01)$ or in either Duraflo II group. The maximal increase of $\mathrm{C} 3 \mathrm{bc}$ after $\mathrm{CPB}$ reached a median of $28 \mathrm{AU} / \mathrm{ml}(18$ to $40 \mathrm{AU} / \mathrm{ml})$ in the CBAS group compared with the median 50 $\mathrm{AU} / \mathrm{ml}(37$ to $58 \mathrm{AU} / \mathrm{ml})$ in the Duraflo II group $(p=0.003)$ (see Fig. 7). In fact, there were no significant differences between the Duraflo II coated group and the uncoated CBAS control group. At 18 hours after the operation, the concentration of $\mathrm{C} 3 \mathrm{bc}$ had returned to baseline levels in all groups.

TCC. The TCC concentration in the CBAS group increased slightly and reached borderline significance compared with baseline $(p=0.048)$. In the 


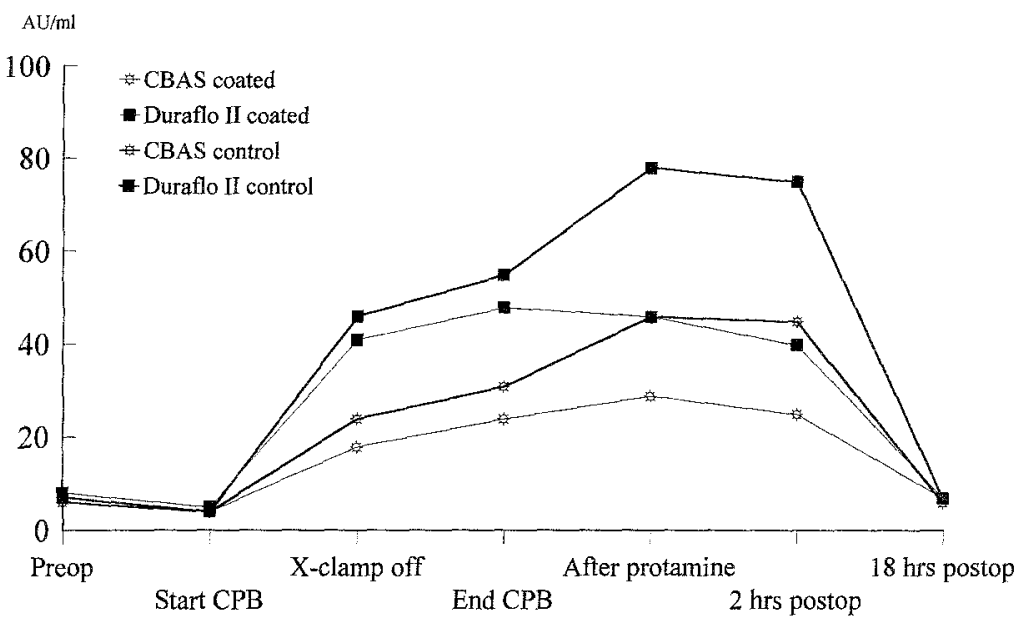

Fig. 3. Time-dependent plasma concentration of the $\mathrm{C} 3$ activation products in all groups. $X$-clamp, Crossclamp.

Table III. Postoperative data of the four groups*

\begin{tabular}{|c|c|c|c|c|}
\hline \multirow[b]{2}{*}{ Postoperative data } & \multicolumn{4}{|c|}{ Median (range) } \\
\hline & $\begin{array}{c}\text { Durafio II coated } \\
\quad(n=17)\end{array}$ & $\begin{array}{l}\text { Duraflo II control } \\
\quad(n=17)\end{array}$ & $\begin{array}{l}\text { CBAS coated } \\
(n=17)\end{array}$ & $\begin{array}{c}\text { CBAS control } \\
(n=16)\end{array}$ \\
\hline Mediastinal drainage $(\mathrm{ml})$ & $620(405-830)$ & $675(355-1305)$ & $615(265-1035)$ & $628(420-1360)$ \\
\hline Homologous transfusions (blood/plasma) & 0 & 0 & 0 & 2 \\
\hline Preop. hemoglobin concentration $(\mathrm{gm} / \mathrm{L})$ & $148(118-178)$ & $146(125-176)$ & $145(129-169)$ & $145(127-165)$ \\
\hline Hemoglobin concentration at discharge $(\mathrm{gm} / \mathrm{L})$ & $121(109-162)$ & $122(96-142)$ & $125(94-142)$ & $116(108-128)$ \\
\hline \multicolumn{5}{|l|}{ Clinical results: } \\
\hline Intubated postop. $(\mathrm{hr})$ & $1.0(0.5-2.3)$ & $1.6(0.8-3.3)$ & $1.5(0.3-3.0)$ & $1.6(0.8-3.3)$ \\
\hline Maximal postop. creatinine concentration ( $\mathrm{mmol} / \mathrm{L})$ & $102(81-159)$ & $97(79-138)$ & $104(84-132)$ & $108(87-142)$ \\
\hline Perioperative myocardial infarction & 0 & 0 & 0 & 1 \\
\hline Mortality & 0 & 0 & 0 & 0 \\
\hline
\end{tabular}

* No significant intergroup differences were detected.

Duraflo II group, however, and in the two control groups, a highly significant increase compared with the baseline level was recognized $(p<0.001)$ (Fig. $4)$. In the CBAS group, the maximal increase of TCC during CPB (see Fig. 7) was a median of 0.8 $\mathrm{AU} / \mathrm{ml}(0.6$ to $1.2 \mathrm{AU} / \mathrm{ml})$ compared with a median of $2.4 \mathrm{AU} / \mathrm{ml}(1.8$ to $2.7 \mathrm{AU} / \mathrm{ml})$ in the Duraflo II group $(p<0.001)$. As with $\mathrm{C} 3 \mathrm{bc}$, there were no significant differences between the Duraflo II coated group and the uncoated CBAS control group. The TCC level returned to preoperative values the day after the operation.

Lactoferrin. An increase of lactoferrin release started from the beginning of the operation, continuing during $\mathrm{CPB}$ to reach a significantly higher level in all groups compared with baseline levels $(p<0.001)$ (Fig. 5). The concentrations in the heparin-coated groups were considerably lower than those of their respective control groups $(p<0.01)$ (see Fig. 7). The maximal release of lactoferrin in the CBAS group was $229 \mu \mathrm{g} / \mathrm{L}(182$ to $341 \mu \mathrm{g} / \mathrm{L})$ and marginally less than the Duraflo II level of $332 \mu \mathrm{g} / \mathrm{L}$ (235 to $451 \mu \mathrm{g} / \mathrm{L})(p=0.05)$. In both control groups, a sudden and significant $(p<0.001)$ decrease of the lactoferrin concentration was seen 2 minutes after protamine administration, with another increase 2 hours later.

Myeloperoxidase. As for lactoferrin, the release of myeloperoxidase increased in all groups from the start of the operations and reached threefold the baseline level at the end of CPB $(p<0.001)$ (Fig. 6). No significant differences were noted between the coated groups and their respective control groups (Fig. 7). A decrease in the levels was observed after protamine administration, but to a much lesser degree than for lactoferrin. 


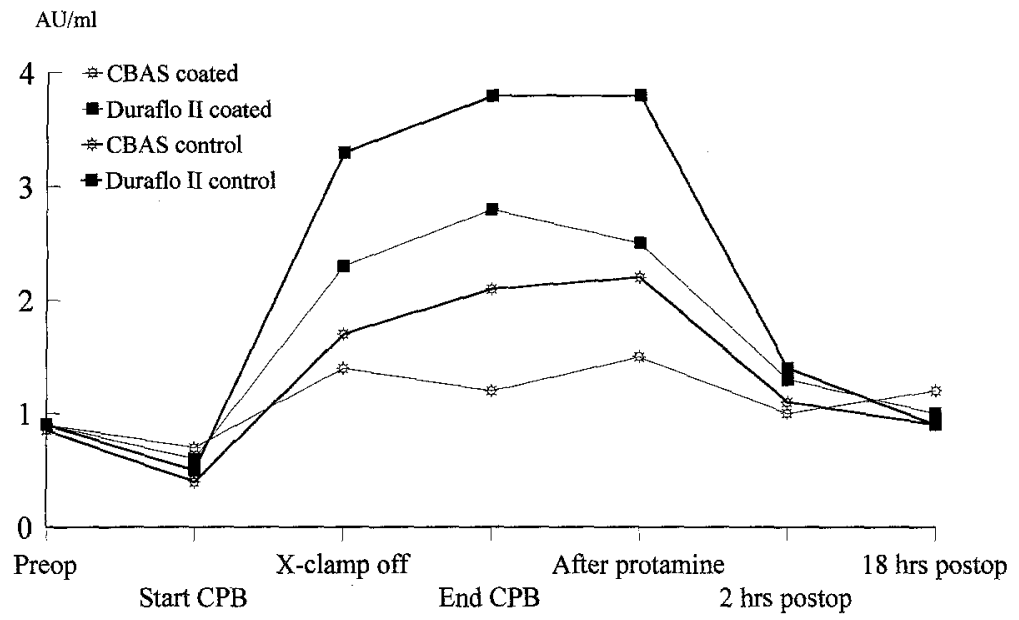

Fig. 4. Time-dependent plasma concentration of SC5b-9 TCC in all groups. $X$-clamp, Crossclamp.

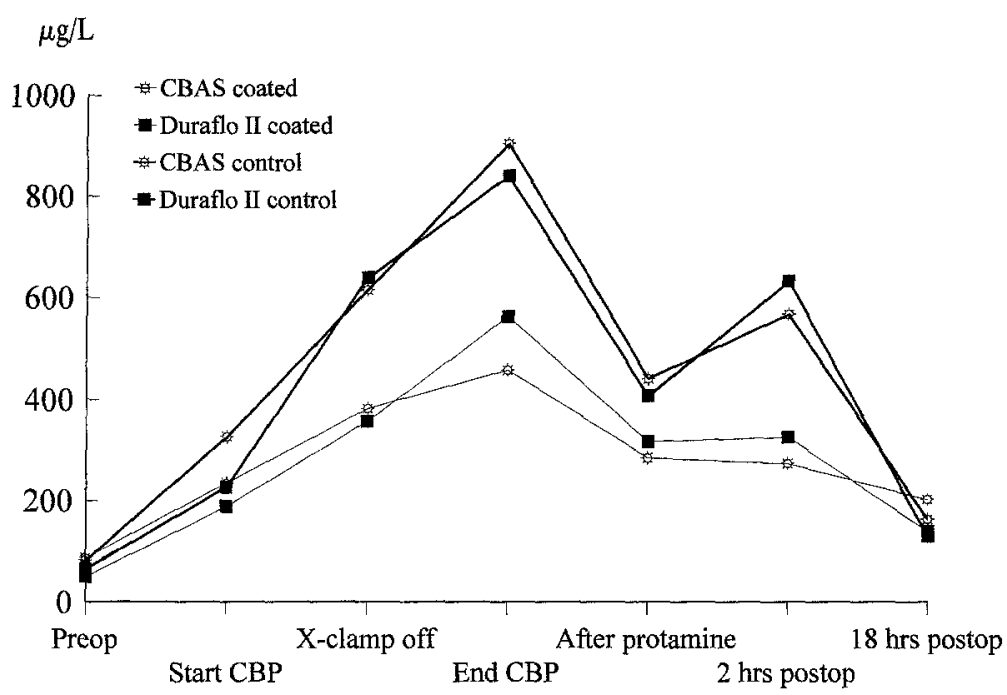

Fig. 5. Time-dependent plasma concentration of lactoferrin in all groups. $X$-clamp, Crossclamp.

The summary results of the most relevant intergroup differences in maximal concentrations of the activation products are given in Table IV.

\section{Discussion}

Heparin coating of nonendothelial surfaces in contact with blood was primarily initiated to improve thromboresistance ${ }^{19}$ but has been documented to reduce activation of several biologic cascades. $^{2-4,12,20}$ Two different processes of coating extracorporeal circuits with immobilized heparin have been developed and are available for clinical use. The CBAS process is based on depositing a polymer coating, polyethylenimine, onto various types of surfaces. Heparin fragments, prepared from the degradation of heparin in nitrous acid, are then end-point attached and covalently bonded to the polymer. ${ }^{11}$ The Duraflo II process is based on the concept of modifying the physiochemical properties of unfractionated heparin with a proprietary binding agent, which has high affinity to a variety of synthetic surfaces. ${ }^{10}$ Direct comparison of blood compatibility of the two differently heparinized circuits has not previously been reported.

Until recently, only the oxygenator and tubings could be coated with heparin, and most clinical studies have been carried out under partly experimental circumstances. In the present study, the 


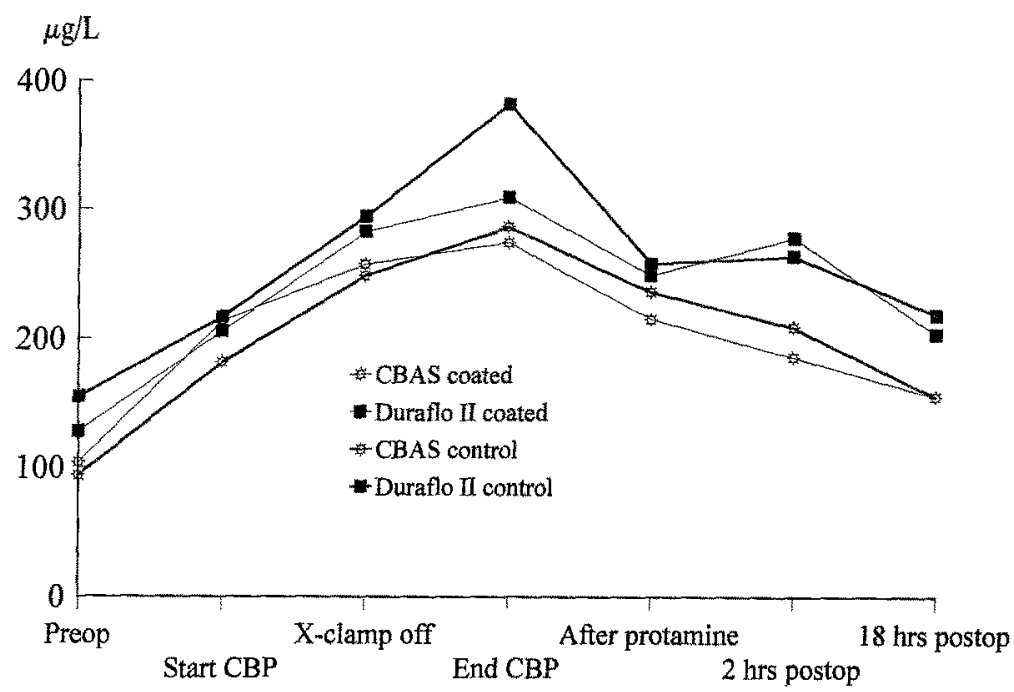

Fig. 6. Time-dependent plasma concentration of myeloperoxidase in all groups. $X$-clamp, Crossclamp.

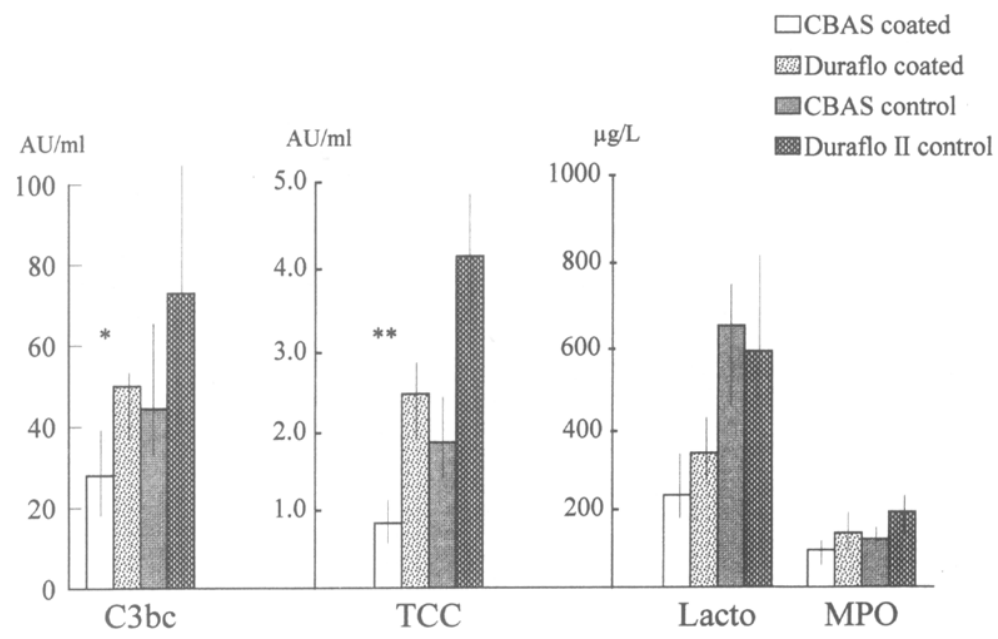

Fig. 7. Maximal increase of the activation markers during the operation in the four groups. The levels were significantly lower in the CBAS group than in the Duraffo II group for $\mathrm{C} 3$ activation products $(\mathrm{C} 3 \mathrm{bc})$ $\left({ }^{*} p=0.003\right)$, and for the SC5b-9 TCC $(* * p<0.001)$. There were marginal differences for lactoferrin (Lacto) $(p=0.05)$, but no difference for myeloperoxidase (MPO). See Table IV for further intergroup differences. Median values with quartiles.

effects on bioactive markers could be investigated in a situation in which all surfaces of the extracorporeal circuit in contact with blood were coated with heparin, including cannulas, lines, filters, and the cardiotomy reservoir.

Significant reduction of complement activation was demonstrated with both heparin-coated circuits compared with their uncoated controls. This observation supports several previous studies of partly heparin-coated circuits ${ }^{2-5,21}$ and is generally ac- cepted as evidence of the improved hemocompatibility when immobilized heparin is attached to artificial surfaces. However, two main distinctions were recognized when the two differently heparinized extracorporeal circuits were compared:

First, the patients in the Duraflo II group required less heparin than the CBAS group to reach the lower limit of ACT. Despite this fact, the plasma concentrations of total circulating heparin during $\mathrm{CPB}$ were significantly higher in the Duraflo II 
Table IV. The percentage reduction of maximal concentrations of the activation products, comparing relevant groups

\begin{tabular}{|c|c|c|c|c|c|c|c|c|}
\hline \multirow[b]{2}{*}{ Groups compared } & \multicolumn{2}{|c|}{$C 3 b c$} & \multicolumn{2}{|c|}{$T C C$} & \multicolumn{2}{|c|}{ Lacto } & \multicolumn{2}{|c|}{$M P O$} \\
\hline & $\%$ & $p$ Value & $\%$ & $p$ Value & $\%$ & $p$ Value & $\%$ & $p$ Value \\
\hline CBAS coated vs. Duraflo II coated & 44 & 0.003 & 67 & $<0.001$ & 31 & 0.05 & 31 & NS \\
\hline CBAS control vs. Duraflo control & 39 & 0.009 & 54 & 0.02 & -9.9 & NS & 37 & 0.04 \\
\hline Duraflo II coated vs. Duraflo II control & 46 & 0.02 & 41 & 0.004 & 43 & 0.002 & 20 & NS \\
\hline CBAS coated vs. CBAS control & 37 & 0.01 & 58 & $<0.001$ & 65 & $<0.001$ & 23 & NS \\
\hline
\end{tabular}

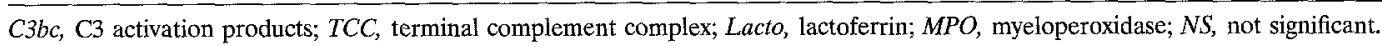

group. This difference is assumed to be due to leaching heparin to the circulation from the Duraflo II surface, and it agrees with an in vitro blood recirculation loop test of coated arterial filters. ${ }^{10}$ About $10 \%$ of the bonded heparin was demonstrated to be circulating shortly after CPB but remained stable at this level for 2 hours.

Second, the patients in the Duraflo II group showed significantly higher concentrations of complement activation products than the CBAS group, both at the intermediate $\mathrm{C} 3$ level and the end of the cascade, as assessed by the concentration of the SC5b-9 TCC. In the CBAS coated group, the levels of $\mathrm{C} 3$ activation products and TCC were lower than those of the Duraflo II coated group, $44 \%$ and $67 \%$, respectively. The same trend was observed for release of lactoferrin. This evidence of different degrees of hemocompatibility may have several reasons, and interpretations of the data are not obvious. Whether leaching of heparin from the coated Duraflo II surface, in contrast to the more stable CBAS coating, ${ }^{11}$ may change the bioactive layer with regard to the surface activation remains to be proved in experimental studies.

One striking observation, however, was that the formation of C3bc and TCC was significantly less prevalent in the uncoated CBAS control group than in the uncoated Duraflo II group. The magnitude of the surface areas in contact with blood could potentially have some influence, but the surfaces were similar in all oxygenators, or even smaller in the Duraflo II groups. These facts clearly demonstrate that the construction and design of the extracorporeal equipment have a major impact on activation of the complement cascade, whether the surfaces are coated with biologic substances or not. Similar conclusions were drawn in a study of complement activation in an in vitro study of six different bubble and membrane oxygenators. ${ }^{22}$ Therefore the reduced activation of complement and granulocytes recognized in the CBAS coated group compared with the Duraflo II group is likely due to a combination of different construction designs of the extracorporeal components and the process for immobilizing heparin to the surfaces.

These findings illustrate the dilemma of the study, when investigating two different coating processes applied to two different types of circuits. For the true effects on blood compatibility of the differently heparinized surfaces to be evaluated, definite studies ideally require "crossover" heparin coating of the two extracorporeal systems. This is probably incompatible with proprietary interests of the manufacturers. So far, the present instruments are the only circuits available for clinical purposes; consequently, documentations of differences in performance and impact on biologic cascades are relevant.

Activation of complement is associated with activation of granulocytes. ${ }^{23}$ Release of cytolytic enzymes contributes to the adverse effects of extracorporeal circulation. ${ }^{24}$ For the activation of granulocytes to be monitored, the release of the glycoproteins lactoferrin and myeloperoxidase were assessed. ${ }^{25}$ Both proteins are mediators of the inflammatory response. In the present study, lactoferrin levels increased rapidly during CPB in all groups. The release was significantly reduced in both heparin-coated groups compared with their control groups. This corresponds with other reports. $^{4,12}$ A marginal difference was observed in favor of less release in the CBAS group than in the Duraflo II group.

Myeloperoxidase release did not differ between the two heparin-coated groups or by comparison with their control groups. This observation is in contrast to other reports. ${ }^{4,12}$ However, inasmuch as the maximal effects of heparin coating on myeloperoxidase release were demonstrated to occur late during $\mathrm{CPB},{ }^{4,12}$ the limited extracorporeal times in our series may explain the differences. Significantly 
less release was seen in the CBAS control group than in the Durafio II control group, again indicating the impact of the design of the circuits.

No evidence of decreased postoperative bleeding was seen when heparin dosages were lowered, as reported by others. ${ }^{8,9}$ The main reason is probably due to the limited number of patients in each group, which precludes any significant conclusions with regard to clinical effects. Moreover, the mediastinal drainage was modest in all groups, including the control groups, and this may mask the influence of the heparin-coated circuits.

In summary, reduced activation of complement and granulocyte release of lactoferrin was demonstrated for both Duraflo II circuits and CBAS circuits used for CPB during coronary artery bypass operations. However, significantly less activation of the complement system was observed for the CBAS group, probably because of the different design of the circuits and the alternative processes for binding heparin to surfaces. The clinical course was uneventful in all groups; however, the patients selected for the study were at low risk, and major complications or organ failures were not expected. The clinical impact of the different patterns of hemocompatibility of the two types of heparinized circuits remains uncertain, but it may be assumed to have consequences in more critically ill patients and in situations requiring long periods of extracorporeal circulation.

We thank Hanne Halvorsen for excellent technical assistance and Hilde Fure for skillful assistance in analyzing the blood samples.

\section{REFERENCES}

1. Videm V, Mollnes TE, Garred P, Svennevig JL. Biocompatibility of extracorporeal circulation: in vitro comparison of heparin coated and uncoated oxygenator circuits. J Thorac CARDiovasc SURG 1991;101: 654-60.

2. Videm V, Svennevig JL, Fosse $E_{\text {, et al. Reduced }}$ complement activation with heparin-coated oxygenator and tubings in coronary bypass operations. $\mathbf{J}$ THORAC Cardiovasc SuRg 1992;103:806-13.

3. Gu YJ, van Oeveren W, Akkerman C, Boonstra PW, Huyzen RJ, Wildevuur CRH. Heparin-coated circuits reduce the inflammatory response to cardiopulmonary bypass. Ann Thorac Surg 1993;55:917-22.

4. Fosse E, Moen O, Johnson E, et al. Reduced complement and granulocyte activation with heparin coated cardiopulmonary bypass. Ann Thorac Surg 1994;58:472-7.

5. Pekna M, Hagman L, Haldèn E, Nilsson UR, Nilsson
B, Thelin S. Complement activation during cardiopulmonary bypass: effect of immobilized heparin. Ann Thorac Surg 1994;58:421-44.

6. Kirklin JK, Westaby S, Blackstone EH, Kirklin JW, Chenoweth DE, Pacifico AD. Complement and the damaging effects of cardiopulmonary bypass. $\mathrm{J}$ THORAC CARDIOVASC SURG 1983;86:845-57.

7. Redmond JM, Gillinov AM, Stuart RS, et al. Heparin-coated bypass circuit reduces pulmonary injury. Ann Thorac Surg 1993;56:474-9.

8. Von Segesser LK, Weiss BM, Pasic M, Garcia E, Turina MI. Risk and benefit of low systemic heparinization during open heart operations. Ann Thorac Surg 1994;58:391-8.

9. Borowiec J, Thelin S, Bagge L, Hultman J, Hansson H-E. Decreased blood loss after cardiopulmonary bypass using heparin-coated circuit and $50 \%$ reduction of heparin dose. Scand J Thorac Cardiovasc Surg 1992;26:177-85.

10. Hsu LC. Principles of heparin-coating techniques. Perfusion 1991;6:209-19.

11. Larm O, Larsson R, Olsson P. A new non-thrombogenic surface prepared by selective covalent binding of heparin via a modified reducing terminal residue. Biomat Med Dev Artif Organs 1983;11:161-73.

12. Borowiec J, Thelin S, Bagge L, Nilsson L, Venge P, Hansson HE. Heparin-coated circuits reduce activation of granulocytes during cardiopulmonary bypass. J Thorac Cardiovasc Surg 1992;104:642-7.

13. Øvrum E, Am Holen E, Abdelnoor M, Øystese R. Conventional blood conservation techniques in 500 consecutive coronary artery bypass operations. Ann Thorac Surg 1991;52:500-5.

14. Garred P, Mollnes TE, Lea T. Quantification of a C3 neoepitope expressed on activated human complement factor C3. Scand J Immunol 1988;27:329-35.

15. Mollnes TE, Lea T, Frøland SS, Harboe M. Quantification of the terminal complement complex in human plasma by an enzyme-linked immunosorbent assay based on monoclonal antibodies against a neoantigen of the complex. Scand J Immunol 1985;22: 197-202.

16. Olofsson T, Olsson I, Venge P, Elgefors B. Serum myeloperoxidase and lactoferrin in neutropenia. Scand J Haematol 1977;18:73-80.

17. Matthews JNS, Altman DG, Campell MJ, Royston P. Analysis of serial measurements in medical research. Br Med J 1990;300:230-5.

18. Kleinbaum D, Kuyper L, Morgenstein H. In: Epidemiologic research: principles and quantitative methods. New York: Van Nostrand Reinhold, 1982.

19. Gott V, Whiffen JD, Datton RC. Heparin bonding on colloidal graphite surfaces. Science 1963;142:1297-8.

20. Gu YJ, van Oeveren W, van der Kamp KWHJ, Akkerman C, Boonstra PW, Wildevuur CRH. Heparin-coating of extracorporeal circuits reduces throm- 
bin formation in patients undergoing cardiopulmonary bypass. Perfusion 1991;6:221-5.

21. Mollnes TE, Videm V, Riesenfeld J, et al. Complement activation and bioincompatibility: the terminal complement complex for evaluation, and surface modification with heparin for improvement of biomaterials. Clin Exp Immunol 1991;88(Suppl 1):21-6.

22. Videm V, Fosse E, Mollnes TE, Ellingsen $\emptyset$, Pedersen T, Karlsen H. Different oxygenators for cardiopulmonary bypass lead to varying degrees of human complement activation in vitro. J THORAC CARDIOVASC SURG 1989;97:764-70.

23. Havermann K, Gramse M. Physiology and pathophys- iology of neutral proteinases of human granulocytes. In: Hörl WH, Heidland A, eds. Proteinases: potential role in health and disease. New York; Plenum press, 1984:1-20.

24. Riegel W, Spillner G, Schlosser V, Hörl W. Plasma levels of main granulocyte components during cardiopulmonary bypass. J THORAC CARDIOVASC SURG 1988; 95:1014-9.

25. Venge P, Nilsson L, Nystrøm SO, Aberg T. Serum and plasma measurements of neutophil granule proteins during cardiopulmonary bypass: a model to estimate human turnover of lactoferrin and myeloperoxidase. Eur J Haematol 1987;39:339-45.

\section{Availability of Journal back issues}

As a service to our subscribers, copies of back issues of THE JOURNAL OF THORACIC AND CARDIOvascular SURGERY for the preceding 5 years are maintained and are available for purchase from the publisher, Mosby-Year Book, Inc., at a cost of $\$ 12.00$ per issue. The following quantity discounts are available: $25 \%$ off on quantities of 12 to 23 , and one third off on quantities of 24 or more. Please write to Mosby-Year Book, Inc., Subscription Services, 11830 Westline Industrial Drive, St. Louis MO 63146-3318, or call (800) 453-4351 or (314) 453-4351 for information on availability of particular issues. If unavailable from the publisher, photocopies of complete issues are available from University Microfilms International, 300 N. Zeeb Rd., Ann Arbor, MI 48106, (313) $761-4700$. 